\title{
SURGICAL TREATMENT FOR FEMOROACETABULAR IMPINGEMENT IN A GROUP THAT PERFORMS SQUATS
}

\author{
Giancarlo Cavalli Polesello', Eduardo Hitoshi Tsuge Cinagawa ${ }^{2}$, Paulo Daniel Sousa Santa Cruz², Marcelo Cavalheiro \\ de Queiroz ${ }^{3}$, Cristian Jandrey Borges ${ }^{4}$, Walter Ricioli Junior ${ }^{3}$, Daniel Daniachi ${ }^{3}$, Rodrigo Pereira Guimarães ${ }^{5}$, \\ Emerson Kiyoshi Honda', Nelson Keiske Ono ${ }^{7}$
}

\begin{abstract}
Objective: Describe the results from arthroscopic surgical treatment on a group of patients who developed symptoms after repetitive physical activity of moving their hips in a position of hyperflexion, as in leg presses and squats. Methods: The study group comprised 47 individuals (48 hips) who developed the onset of painful symptoms associated with hip hyperflexion exercises (leg presses or squats) and underwent arthroscopic treatment. The patients were evaluated radiographically and clinically according to the "Harris Hip Score", as modified by Byrd (MHHS), pre and postoperatively, and were asked about their return to sports activities and the surgical findings. Results: The mean preoperative and postoperative MHHS,
\end{abstract}

respectively, were 60 points (SD 11.0, range 38.5 to 92.4 ) and 95.9 points (SD 7.7, range 63.8 to 100 ), with an increase of 35.9 points $(\mathrm{P}<0.001)$. Regarding physical activity, 30 individuals $(71.5 \%)$ resumed sports activities after surgery, and 25 of them $(83.4 \%)$ at the previous level. Six patients (12.8\%) did not resume activities because of persistent pain. During arthroscopy, 48 hips (100\%) presented lesions of the acetabular labrum, and 41 hips (85.4\%) had acetabular chondral lesions. Conclusion: The patients with painful symptoms after hip hyperflexion exercises associated with femoroacetabular impingement presented improvements after arthroscopic treatment.

Keywords - Arthroscopy; Hip Joint; Hip Injuries; Acetabulum

\section{INTRODUCTION}

In 1936, Smith-Petersen described how bone deformities in the proximal femur and in the acetabulum might be responsible for degeneration of the hip joint $^{(1)}$. Femoroacetabular impact (FAI) was only recently also described as a proven cause of hip osteoarthrosis $^{(2)}$. The theoretical basis for the physiopathological correlation between bone deformities and joint lesions as the consequent degeneration has been investigated ${ }^{(3)}$ and computer graphic models have validated this theory ${ }^{(4)}$. Abnormalities of pelvic mobility have repercussions on the hip biomechanics of patients with $\mathrm{FAI}^{(5)}$ and can be shown at the time of open surgery ${ }^{(3)}$. Over the range of motion of the hip joint, hyperflexion with internal rotation is the position most association with this impact ${ }^{(6)}$.

FAI causes intra-articular soft-tissue lesions, especially to the cartilage of the acetabular labrum and the capsular ligament cartilage ${ }^{(2,3)}$. However, it is unclear whether the lesions occur due to repeated movements of the load, thus causing an impact, or whether they occur as a result of isolated axial loading episodes with internal rotation of the hip. A third possibility is repetitive torsion or turning of the hip in a moderately flexed or extended position, even in the absence of $\mathrm{FAI}^{(7)}$.

\footnotetext{
1 - PhD. Assistant Professor and Head of the Hip Group, School of Medical Sciences, Santa Casa de São Paulo (FCMSCSP), São Paulo, SP, Brazil.

2 - Resident in Orthopedics, School of Medical Sciences, Santa Casa de São Paulo (FCMSCSP), São Paulo, SP, Brazil.

3 - Orthopedist and Attending Physician in the Hip Group, School of Medical Sciences, Santa Casa de São Paulo (FCMSCSP), São Paulo, SP, Brazil.

4 - Orthopedist and former trainee in the Hip Group, School of Medical Sciences, Santa Casa de São Paulo (FCMSCSP), São Paulo, SP, Brazil.

5 - MSc. Instructor-Professor and Attending Physician in the Hip Group, School of Medical Sciences, Santa Casa de São Paulo (FCMSCSP), São Paulo, SP, Brazil.

6 - PhD. Teaching Instructor and Senior Member of the Hip Group, School of Medical Sciences, Santa Casa de São Paulo (FCMSCSP), São Paulo, SP, Brazil.

7 - PhD. Adjunct Professor and Senior Member of the Hip Group, School of Medical Sciences, Santa Casa de São Paulo (FCMSCSP), São Paulo, SP, Brazil.

Work performed by the Hip Group, Department of Orthopedics and Traumatology, School of Medical Sciences, Santa Casa de São Paulo (FCMSCSP).

Correspondence: Rua Barata Ribeiro 414, Cj. 23, 01308-000 São Paulo, SP, Brazil. E-mail: giancarlopolesello@hotmail.com
}

Work received for publication: October 22, 2011; accepted for publication: November 21, 2011.

The authors declare that there was no conflict of interest in conducting this work 
The motivation for this study was the clinical observation that some patients develop acute symptoms on performing squatting or leg press exercises, and this has become increasingly common in medical consultation offices.

At excessive angles, the movements reproduce the mechanism that provokes joint lesions in patients with hip dysmorphism. So far, no screening mechanism has been established for identifying individuals who potentially might have morphological abnormalities of the proximal femur and the acetabulum. Asymptomatic individuals with a dysmorphic hip may, without such knowledge, be harmed by new lesions or worsening of preexisting hip lesions after performing this type of exercise, and this formed our hypothesis for the present study.

The aim of the present study was to report on a series of cases of patients with FAI who developed symptoms in these activities, and their surgical treatment.

\section{METHODS}

This was a retrospective study on a group of 47 patients with FAI (48 hips) who developed symptoms associated with hip hyperflexion exercises, including leg press and squatting exercises, with a minimum follow-up of 12 months. This study was approved by our institution's ethics committee. The patients' medical files were reviewed, along with the documents from all imaging examinations (both radiographic and video-arthroscopic).

The patients' mean age was 36 years (minimum of 18 and maximum of 54 years). Twenty patients were male $(42.5 \%)$ and 27 were female $(57.5 \%)$. In relation to sports activities, all the patients habitually attended gyms and $42(89.3 \%)$ used the gyms to practice a variety of sports activities. The length of follow-up ranged from 12 to 88 months (mean of 34.3 months). The right side was affected in 25 cases $(52 \%)$ and the left side in 23 cases (48\%), and there was a single case $(2 \%)$ of bilateral involvement.

Regarding clinical characteristics, the patients were asked about their sports activities before the pain began; the relationship between the appearance of pain and starting to perform squatting and leg press exercises; their return to sports activities and to the gym after surgery; their return to performing squatting and leg press exercises; and their satisfaction with the surgical treatment. All the patients were assessed using the Harris Hip Score, as modified by Byrd (MHHS $^{(8)}$, before and after the operation. From this assessment, the results were stratified as follows: poor (MHHS < 70 points), fair (MHHS 70-79 points), good (80-89 MHHS points) and excellent (90-100 points MHHS $)^{(9)}$.

Hip radiographs in the anteroposterior view ${ }^{(10)}$ and Ducroquet lateral view ${ }^{(11)}$ were analyzed and the following were measured: center-edge (CE) angle ${ }^{(12)}$, alpha angle ${ }^{(13)}$, presence of crossover $\operatorname{sign}^{(14)}$, presence of the ischial spine $\operatorname{sign}^{(15)}$ and presence of the posterior wall sign ${ }^{(15)}$. Presence of radiographic arthrosis was classified according to the criteria of Tönnis et $\mathrm{al}^{(16)}$.

The $\mathrm{CE}$ angle ranged from $22^{\circ}$ to $51^{\circ}$, with a mean of $35.8^{\circ}\left(\mathrm{SD}=6.9^{\circ}\right) ; 15$ hips $(31.2 \%)$ had a $\mathrm{CE}$ angle $\geq 40^{\circ} ; 29$ hips $(60.4 \%)$ between $25^{\circ}$ and $40^{\circ}$; and four hips $(8.3 \%) \leq 25^{\circ}$.

The alpha angle ${ }^{(13)}$ ranged from $46^{\circ}$ to $86^{\circ}$, with a mean of $65.6^{\circ}\left(\mathrm{SD}=7,4^{\circ}\right) ; 47$ hips $(97.9 \%)$ presented an alpha angle $\geq 50^{\circ}$.

Regarding the presence of the crossover sign, ischial spine sign and posterior wall sign, the results were positive in $70.8 \%, 72.9 \%$ and $43.7 \%$ of the individuals, respectively.

The types of impact were divided radiographically into pincer and cam. The term 'cam' comes from mechanics and relates to transformation of a circular movement into a linear movement, caused by the presence of bulging or hollowing, like in the crankshaft of an engine. The 'pincer' type occurs as a linear contact between the acetabular margin and the cervicocephalic junction $^{(17)}$. Thirty-seven cases $(77 \%)$ were classified as mixed type, and eleven (23\%) as cam type. None of the cases were classified as pincer type alone.

Using the classification of Tönnis et $\mathrm{al}^{(16)}, 36$ hips $(75 \%)$ were grade 0 , nine $(18.7 \%)$ were grade I, two $(4.2 \%)$ were grade II and only one $(2.1 \%)$ was grade III.

Regarding the arthroscopic findings, the presence of bone deformities on the acetabular margin and femoral neck, deformities of the round ligament, femoral or acetabular chondral lesions and lesions of the acetabular labrum were analyzed. For chondral lesions, the Outerbridge classification was used ${ }^{(18)}$.

The statistical method used was Student's t test 
(SPSS version 10.0, SPSS, Chicago, Illinois, USA), and $\mathrm{P}<0.001$ was taken to be statistically significant. The MHHS values before and after the surgery were analyzed.

\section{RESULTS}

\section{Clinical characteristics}

The mean preoperative MHHS was 60 points (SD 11.0; range 38.5 to 92.4 ), while the mean postoperative MHHS was 95.9 points (SD 7.7; range 63.8 to 100). The difference between the pre and postoperative MHHS was statistically significant. The mean increase in MHHS from before to after the operation was 35.9 points (Table 1).

According to the stratified MHHS assessment, 39 individuals had excellent results $(82.9 \%)$; six, good $(12.9 \%)$; one, fair $(2.1 \%)$; and one, poor $(2.1 \%)$. Six individuals $(12.8 \%)$ were dissatisfied with the surgical treatment because of persistent pain; and one $(2.1 \%)$ presented pain only when performing activities (Figure 1).

Regarding physical activities, 30 patients $(71.5 \%)$ returned to their sports activities after the surgery, of whom $25(83.4 \%)$ returned to the same level as before, while five $(16.6 \%)$ modified their practices. Thirty-five patients $(74.5 \%)$ returned to the gym under technical supervision (Figure 2).

Table 1 - Assessment on patients who underwent arthroscopic treatment of femoroacetabular impact, according to the MHHS.

\begin{tabular}{c|c|c|c|c|c|c}
\hline MHHS & $\mathbf{n}$ & Mean & $\begin{array}{c}\text { Standard } \\
\text { deviation }\end{array}$ & Minimum & Maximum & $\mathbf{p}$ \\
\hline Preoperative & 48 & 60 & 11 & 38.5 & 92.4 & $<0.001^{*}$ \\
\hline Postoperative & 48 & 95.9 & 7.7 & 63.8 & 100 & \\
\hline
\end{tabular}

*t-teste de Student (SPSS versão 10.0, SPSS, Chicago, Illinois, EUA).

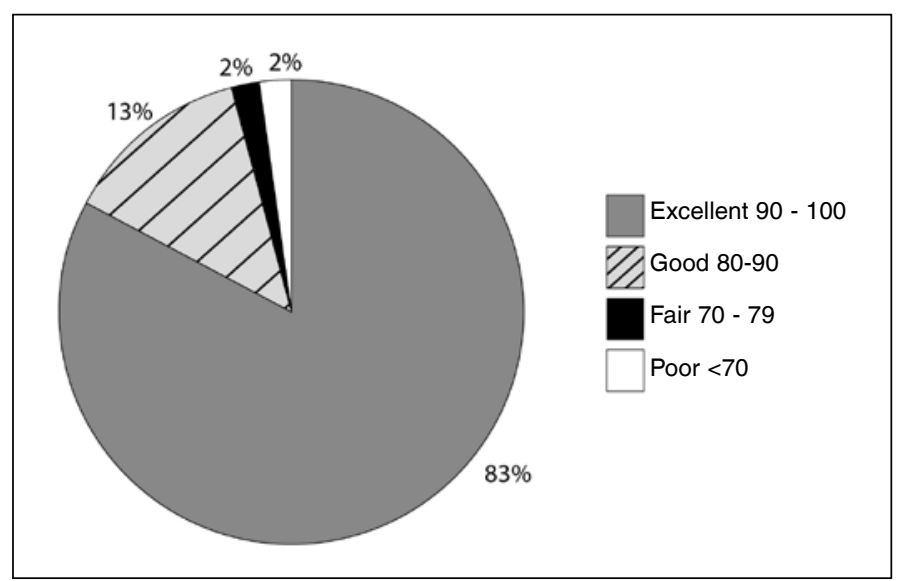

Figure 1 - Final MHHS assessment.

Rev Bras Ortop. 2012;47(4):488-92

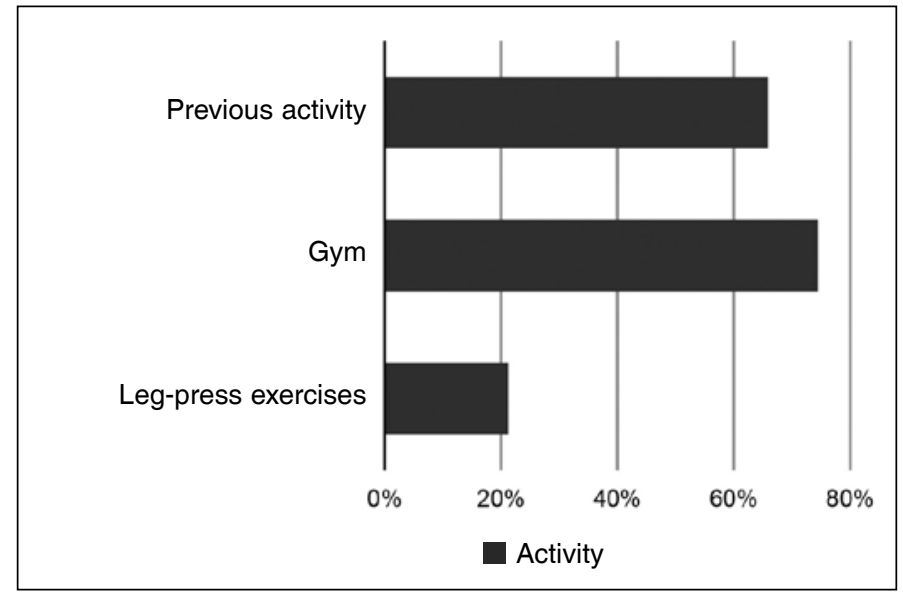

Figure 2 - Postoperative physical activity.

\section{Surgical characteristics}

During the arthroscopy, 48 hips $(100 \%)$ were found to present lesions on the acetabular labrum and 41 hips (85.4\%), acetabular chondral lesions. All of these were classified as Outerbridge grade $\mathrm{IV}^{(18)}$ and were subjected to debridement until stabilization was achieved. In the other seven hips, the lesions were considered to be stable, and there was no delamination at the osteochondral interface. On two hips (4.1\%) lesions of the cartilage of the proximal femur were observed and on seven hips (14.6\%), lesions of the round ligament.

Characteristic pincer-like lesions were observed at the acetabular margin in 30 hips (62.5\%), and acetabular osteoplasty was performed in these cases. In 23 cases $(76.6 \%)$, the acetabular labrum was reinserted, with suturing. Eleven cases of cam-like deformities (23\%) and 37 of mixed type (77\%) were found, and osteoplasty was performed to treat them and protect the labral suturing (Figure 3).

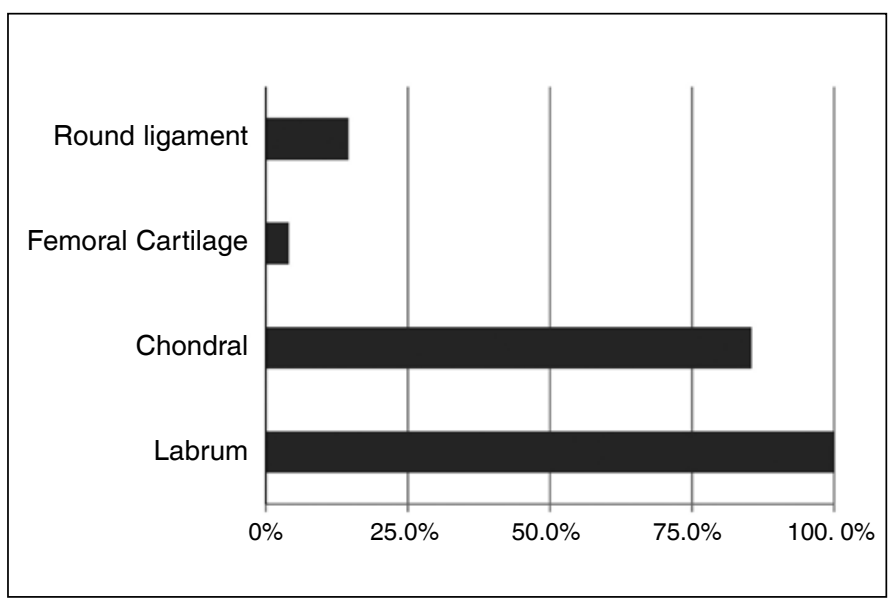

Figure 3 - Intraoperative pathological findings. 


\section{DISCUSSION}

FAI is a source of incapacity among young athletes ${ }^{(19)}$, and intense sports activity practice increases the risk of hip osteoarthrosis ${ }^{(19)}$. After a mean of 10 to 20 years of sports activities, professional or amateur athletes (sports such as running or jumping, and sports with repetitive impact) present a risk of coxarthrosis that is two to four times greater than what is observed in the general population ${ }^{(3)}$. Sports with repetitive impact, such as soccer, volleyball, handball, basketball, rugby, tennis, long-distance running, hurdling, judo, karate and dancing, present an even higher risk of osteoarthrosis ${ }^{(19)}$. Knowledge of the physiopathology of FAI suggests that by treating it, it becomes possible to delay or even avoid development of arthrosis ${ }^{(20)}$. The therapeutic success achieved with open surgery ${ }^{(3)}$, and more recently, with arthroscopic treatment ${ }^{(21)}$, has stimulated many studies on sports injuries caused by $\mathrm{FAI}^{(22)}$.

In the group of patients of the present study, $89.7 \%$ were performing sports activities and exercises in gyms, thus making this an extremely active group. This group achieved a significant improvement after the operation, with a mean of 35.9 points according to the MHHS, which was consistent with the most recent published results ${ }^{(10,22,23)}$. The dissatisfaction rate of $12.8 \%$ regarding the surgical treatment was only correlated with low initial MHHS in one of the six cases, and only one patient presented worsening of the MHHS. It should be noted that one of the dissatisfied patients presented an improvement in MHHS from 61 to 95 points, and another from 56 to 84 points, and the pain related only to performing sports activities. This also leads us to question the criteria needed for satisfying these patients ${ }^{(24)}$. It has to be emphasized that the Harris Hip Score presents limitations with regard to evaluating groups of young and active patients who often have high demands for athletic performance, even after modification of the score by Byrd and Jones ${ }^{(8,25)}$.

The patients' gym return rate of $74.5 \%$ and their satisfaction rate with the surgical results of $87.2 \%$ support the concept that returning to sports activities is viable ${ }^{(17)}$.

Practicing other sports that do not involve performing leg presses was taken into consideration as one of the variables, but the fact that the patients made a direct correlation between appearance of pain and performing leg press or squatting exercise strengthens the hypothesis that this association exists. Moreover, after the operation, patients who were appropriately instructed how to perform leg press or squatting exercises, i.e. avoiding hyperflexion of the hip beyond 90 degrees, continued to perform the exercises without any return of the symptoms.

The cam and pincer lesion patterns differ substantially regarding the type of torque on the acetabular labrum. In the cam type, there is abrasion of the cartilage from outside to inside or delamination ${ }^{(25)}$. It is important to emphasize that although the great majority of the patients did not present radiographic arthrosis, $100 \%$ had lesions of the acetabular labrum and $85 \%$ had chondral lesions in the acetabulum, which makes us believe that FAI has silent but destructive potential and that early diagnosis is necessary in order to obtain good results from the treatment.

We believe that if exercises like squatting and leg presses are badly performed, they can be very harmful when associated with occurrences of FAI, especially in patients who do not know that they present hip dysmorphism. Activities that require extreme flexion of the hip cause the anterosuperior portion of the femoral head to penetrate the acetabulum. Thus, for patients with cam-like dysmorphism or impact, their protuberance at the femoral head-neck junction also strikes the periphery of the acetabulum ${ }^{(26)}$. The pain occurs after the onset of the "outside to inside" lesions of the cartilage and the lesions at the chondrolabral junction of the acetabulum. It is significant that $91 \%$ of the patients had an alpha angle greater than 50 degrees. Squatting at maximum depth and leg presses are exercises that require a large range of motion in the hip and pelvis, coming close to the maximum in individuals with $\mathrm{FAI}^{(4,20)}$. Lamontagne et $\mathrm{al}^{(5)}$ measured the cam effect on FAI in a three-dimensional movement of the hip and pelvis during squatting at maximum depth, in comparison with a healthy control group. Patients with FAI did not present differences in hip movement during the squatting, but had a smaller pelvic sagittal range of motion, in relation to the control group ${ }^{(20,27)}$. Sagittal pelvic mobility is an integral part of the trunk flexion movements for maintaining balance and thus allowing the large hip flexion angles that are essential for deep squatting. A reduced sagittal field may predispose towards premature contact between the proximal femur and the acetabular margin, especially in movements that demand high 
levels of hip flexion ${ }^{(28)}$. In the group with FAI, the ability to squat was less than in the control group. These results show that pelvic mobility may also be partially responsible for abnormal contact between the anterosuperior acetabulum and the proximal femur ${ }^{(29)}$.

Given the observation of this study, we recommend that healthcare professionals should pay special attention to this type of athlete. Such individuals should be examined to identify diminished internal rotation when the hip is flexed at 90 degrees. In these cases, the diagnosis of hip dysmorphism is possible and radiographic evaluated is recommended for confirming this.

Comprehension of the relationship between squatting exercises and FAI can be used to modify the exercises, so as to enable: 1) prevention among asymptomatic athletes with positive results from screening for FAI; 2) treatment among athletes with symptomatic FAI; and 3) guidance among athletes who have already undergone surgical correction of FAI.
This study has limitations. It was a retrospective study on a case series, without a control group, which does not allow us to reach conclusive results. Moreover, other variables that might also have caused FAI could not be controlled for.

\section{CONCLUSION}

The assessment on patients with painful symptoms after hip hyperflexion exercises, in association with presence of FAI, showed that these patients presented improvements following arthroscopic treatment. Further studies are needed in order to prove that hip hyperflexion exercises are a causal factor for FAI.

\section{ACKNOWLEDGEMENTS}

We thank Dr. J.W. Thomas Byrd and Dr. Patrícia M.M. Fuccs for reviewing the study and for their valuable comments.

\section{REFERENCES}

1. Smith-Petersen MN. The classic: Treatment of malum coxae senilis, old slipped upper femoral epiphysis, intrapelvic protrusion of the acetabulum, and coxa plana by means of acetabuloplasty. 1936. Clin Orthop Relat Res. 2009;467(3):608-15.

2. Ganz R, Parvizi J, Beck M, Leunig M, Notzli H, Siebenrock KA. Femoroacetabular impingement: A cause for osteoarthritis of the hip. Clin Orthop Relat Res. 2003;(417):112-20.

3. Beck M, Kalhor M, Leunig M, Ganz R. Hip morphology influences the pattern of damage to the acetabular cartilage: Femoroacetabular impingement as a cause of early osteoarthritis of the hip. J Bone Joint Surg Br. 2005;87(7):1012-8.

4. Tannast M, Goricki D, Beck M, Murphy SB, Siebenrock KA. Hip damage occurs at the zone of femoroacetabular impingement. Clin Orthop Relat Res. 2008;466(2):273-80.

5. Lamontagne M, Kennedy MJ, Beaule PE. The effect of cam FAI on hip and pelvic motion during maximum squat. Clin Orthop Relat Res. 2009;467(3):645-50.

6. Flanagan S, Salem GJ, Wang MY, Sanker SE, Greendale GA. Squatting exercises in older adults: Kinematic and kinetic comparisons. Med Sci Sports Exerc. 2003;35(4):635-43.

7. Crawford MJ, Dy CJ, Alexander JW, Thompson M, Schroder SJ, Vega CE, et al. The 2007 frank stinchfield award. the biomechanics of the hip labrum and the stability of the hip. Clin Orthop Relat Res. 2007;(465):16-22.

8. Byrd JW, Jones KS. Prospective analysis of hip arthroscopy with 2-year follow-up. Arthroscopy. 2000;16(6):578-87.

9. Leunig M, Ganz R. Femoroacetabular impingement. A common cause of hip complaints leading to arthrosis. Unfallchirurg. 2005;108(1):9-10, 12-7.

10. Larson CM, Giveans MR. Arthroscopic management of femoroacetabular impingement: Early outcomes measures. Arthroscopy. 2008;24(5):540-6.

11. Godefroy D, Chevrot A, Morvan G, Rousselin B, Sarazin L. Plain films of pelvis. J Radiol. 2008;89(5 Pt 2):679,90.

12. Wiberg G. Studies on dysplastic acetabulum and congenital subluxation of the hip joint with special reference to the complication of osteoarthritis. Acta Chir Scand. 1939; 83 (Suppl 58):1-135.

13. Nötzli HP, Wyss TF, Stoecklin CH, Schmid MR, Treiber K, Hodler J. The contour of the femoral head-neck junction as a predictor for the risk of anterior impingement. $\mathrm{J}$ Bone Joint Surg Br. 2002;84(4):556-60.

14. Tannast M, Siebenrock KA, Anderson SE. Femoroacetabular impingement: radiographic diagnosis--what the radiologist should know. AJR Am J Roentgenol. 2007;188(6):1540-52.

15. Kalberer F, Sierra RJ, Madan SS, Ganz R, Leunig M. Ischial spine projection into the pelvis: A new sign for acetabular retroversion. Clin Orthop Relat Res. 2008;466(3):677-83.

16. Tönnis D, Legal H, Graf R. Congenital dysplasia and dislocation of the hip in children and adults. Berlin: Springer-Verlag; 1987.

17. Lavigne M, Parvizi J, Beck M, Siebenrock KA, Ganz R, Leunig M. Anterior femoroacetabular impingement: part I. Techniques of joint preserving surgery. Clin Orthop Relat Res. 2004;(418):61-6.

18. Outerbridge RE. The etiology of chondromalacia patellae. 1961. Clin Orthop Relat Res. 2001;(389):5-8.

19. Brunner A, Horisberger M, Herzog RF. Sports and recreation activity of patients with femoroacetabular impingement before and after arthroscopic osteoplasty. Am J Sports Med. 2009;37(5):917-22.

20. Compaore C, Chevalier X, Lequesne M. Les facteurs de risque de survenue de la coxarthrose. Rev Rhum. 2009;76(4):325-30.

21. Ganz R, Leunig M, Leunig-Ganz K, Harris WH. The etiology of osteoarthritis of the hip: An integrated mechanical concept. Clin Orthop Relat Res. 2008;466(2):264-72.

22. Philippon MJ, Weiss DR, Kuppersmith DA, Briggs KK, Hay CJ. Arthroscopic labral repair and treatment of femoroacetabular impingement in professional hockey players. Am J Sports Med. 2010;38(1):99-104.

23. Byrd JW, Jones KS. Arthroscopic femoroplasty in the management of cam-type femoroacetabular impingement. Clin Orthop Relat Res. 2009;467(3):739-46.

24. Philippon MJ, Briggs KK, Yen YM, Kuppersmith DA. Outcomes following hip arthroscopy for femoroacetabular impingement with associated chondrolabral dysfunction: Minimum two-year follow-up. J Bone Joint Surg Br. 2009;91(1):16-23.

25. Martin RL, Mohtadi NG, Safran MR, Leunig M, Martin HD, McCarthy J, et al. Differences in physician and patient ratings of items used to assess hip disorders. Am J Sports Med. 2009;37(8):1508-12.

26. Leunig M, Beaule PE, Ganz R. The concept of femoroacetabular impingement: Current status and future perspectives. Clin Orthop Relat Res. 2009;467(3):616-22.

27. Bizzini M, Notzli HP, Maffiuletti NA. Femoroacetabular impingement in professional ice hockey players: A case series of 5 athletes after open surgical decompression of the hip. Am J Sports Med. 2007;35(11):1955-9.

28. Beck M, Leunig M, Parvizi J, Boutier V, Wyss D, Ganz R. Anterior femoroacetabular impingement: Part II. midterm results of surgical treatment. Clin Orthop Relat Res. 2004;(418):67-73.

29. Ilizaliturri VM Jr, Orozco-Rodriguez L, Acosta-Rodriguez E, Camacho-Galindo J. Arthroscopic treatment of cam-type femoroacetabular impingement: Preliminary report at 2 years minimum follow-up. J Arthroplasty. 2008;23(2):226-341. 